war in spätern Makedonien wohnhaft ${ }^{40}$ ). Auch hier fällt es nicht schwer die ionischen spuren nachzuweisen; alugesehen von einzelnen namen wie z. b. Aegae liegt hart am pelagonischen gebiete die Iandschaft der Almonen oder Almopen, über deren minyeisch aeolische abkunft kein zweifel stattfindet ${ }^{41}$ ). Wie eng aber die Aeolier und Minyer mit den Joniern verwandt sind, darüber bedarf es nach Curtius keiner weiteren ausführung ${ }^{42}$ ).

Doberan. Moriz Crain.

40) Schon O. Abel (Makedonien vor könig Philipp p. 32) stellte beide völker zusammen, freilich ohne dass seine sprachlichen deduclionen genügen könnten. Der ferner von ihm beigebrachte Pelops (vergl. Bu:tnann Lexilogus I p. 68) gehört aber durchaus nicht hieher. Ob die wurzel $\pi \neq \lambda r y$ eine weiterbildung von $\pi * a$ sei, isl eine secundäre frage.

41) Vgl. O. Müler Orchomenos p. 140. O. Abel Maked. p. 145.

42) Die Ionier p. 24 und 41.

\title{
Zu Libanius.
}

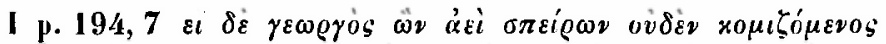

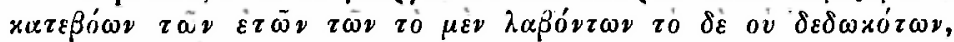

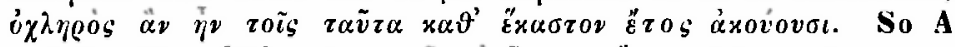
und B. Man fühlt, dass $\tau \tilde{\omega} \nu$ $\varepsilon \tau \tilde{\omega} \nu$ zu $\tilde{\varepsilon}^{\prime} z o s$ nicht recht passt;

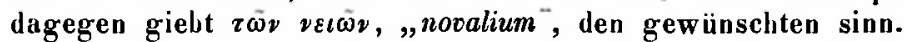

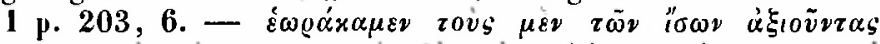

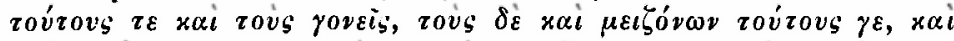

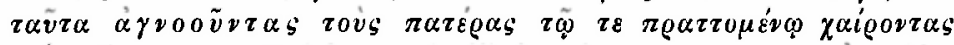
$x \tau \varepsilon$. Dazu sagt Reiske: ,sic libri mei onnes. verum ovx vide-

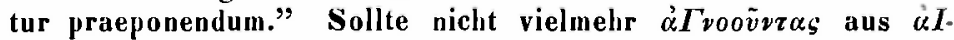

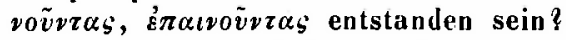

1 p. 226, 22 lheisst es in der wegen eines lebensereignisses des sophisten höchst interessanten lobrede auf Artemis: "z $\lambda \alpha \varphi o i$

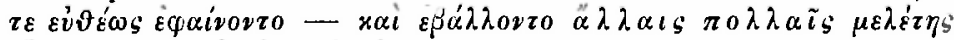

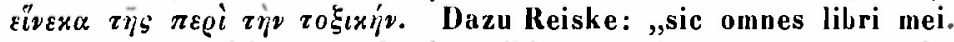
verum tamen vitiosa est lectio. mihi certe obscura. neque satis.

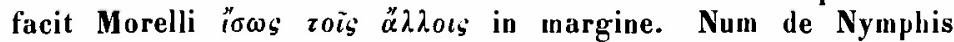
Dianae comitibus loquitur?" Die libri werden wohl das richtige haben, aber die lierrn gelehrten falsch gelesen haben: $\alpha \lambda \lambda \alpha \iota c$ -

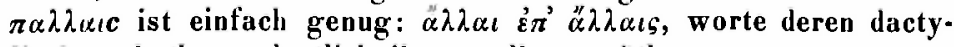
lischer rhythmus deutlich ihre quelle verräth.

Oels.

M. Schmidt. 